\title{
Muscle activation in pelvic anteversion and retroversion
}

\author{
Ativação muscular durante a \\ anteversão e retroversão pélvica
}

\author{
Bibiana Melher Pereira (1) ${ }^{1,2}$ \\ Marcelo Peduzzi de Castro (iD ${ }^{3}$ \\ Cristiano Gomes Sanchotene (10 ${ }^{4}$ \\ Caroline Ruschel (1) ${ }^{4}$ \\ Gilmar Moraes Santos $\mathbb{1 D}^{1,2,4^{*}}$
}

\footnotetext{
1 Universidade do Estado de Santa Catarina (UDESC), Graduate Program in Physiotherapy (PPGFT), Florianópolis, SC, Brazil

2 Posture and Balance Laboratory, Florianópolis, SC, Brazil

${ }^{3}$ LaBClin - Laboratory of Clinical Biomechanics and Neuromusculoskeletal Rehabilitation, Florianópolis, SC, Brazil

${ }^{4}$ Universidade do Estado de Santa Catarina (UDESC), Graduate Program in Human Movement Science (PPGCMH), Florianópolis,SC, Brazil
}

Date of first submission: January 18, 2021

Last received: June 18, 2021

Accepted: June 22, 2021

Associate editor: Aldo Fontes-Pereira

*Correspondence: gilmar.santos@udesc.br

\begin{abstract}
Introduction: The inability to maintain good pelvic stability has been attributed to inefficient muscle coordination and deconditioning of the stabilizing muscles. Despite this, little is known about the role of the pelvic muscles in anteversion and retroversion movements. Objective: To compare the neuromuscular activity of the tensor fascia lata, gluteus medius, upper and lower portions of the gluteus maximus, and multifidus in pelvic anteversion and retroversion. Methods: The neuromuscular activity of 17 healthy young adults (aged $25.3 \pm 4.6$ years) was assessed during five repetitions of the pelvic anteversion and retroversion movements. The Vicon-Nexus system (10 cameras) was used for the kinematic analysis of the pelvis in the sagittal plane (anteversion and retroversion), and the TeleMyo DTS Desk Receiver electromyograph and the Myomuscle v. 3.8 software to measure neuromuscular activity. The paired samples t-test was used to compare muscle activity between pelvic anteversion and retroversion movements using the Statistica v. 8 software with a significance level of $p<0.05$. Results: The comparison of the movements showed greater muscle activity in the inferior gluteus maximus in retroversion and greater activity in the multifidus in pelvic anteversion. The upper portion of the gluteus maximus showed relevant activation in both movements. Conclusion: There was more pronounced activity of the lower portion of the gluteus maximus in retroversion, while the upper gluteus maximus showed relevant activation level in both movements. The multifidi were more active in retroversion.
\end{abstract}

Keywords: Electromyography. Motor activity. Pelvis. 


\section{Resumo}

Introdução: $A$ incapacidade de manter uma boa estabilidade pélvica tem sido atribuída à coordenação muscular ineficiente e ao descondicionamento dos músculos estabilizadores. Apesar disso, pouco se sabe sobre a função dos músculos pélvicos nos movimentos de anteversão e retroversão. Objetivo: Comparar a atividade neuromuscular do tensor da fáscia lata, glúteo médio, porções inferior e superior do glúteo máximo e multífidos durante a anteversão e retroversão pélvica. Métodos: $A$ atividade neuromuscular de 17 adultos jovens saudáveis (25,3 \pm 4,6 anos) foi avaliada durante cinco repetições dos movimentos de anteversão e retroversão pélvica. Utilizou-se o sistema ViconNexus (10 câmeras) para a análise cinemática da pelve no plano sagital (anteversão e retroversão), e o eletromiógrafo TeleMyo DTS Desk Receiver e o software MyoMuscle v. 3.8 para mensurar a atividade neuromuscular. Testes $t$ pareados foram conduzidos para comparar a atividade muscular entre os movimentos de anteversão e retroversão pélvica, utilizando-se o software Statistica v.8 com nível de significância de $p<0,05$. Resultados: Quando comparados os movimentos, maior atividade muscular foi observada para o glúteo máximo inferior durante a retroversão e maior atividade para os multífidos durante a anteversão pélvica. $A$ porção superior do glúteo máximo apresentou ativação relevante em ambos os movimentos. Conclusão: Houve atividade mais pronunciada da porção inferior do glúteo máximo na retroversão enquanto o glúteo máximo superior apresentou nível relevante de ativação em ambos os movimentos; os multífidos se mostraram mais ativos na retroversão.

Palavras-chave: Eletromiografia. Atividade motora. Pelve.

\section{Introduction}

The transmission of ground reaction forces along the lower limbs and spine during dynamic tasks depends on good pelvic control, i.e., on an adequate stabilization capacity. Even though the trunk musculature plays an important role in this stability, inadequate control of the pelvis can affect the transmission of forces through the kinetic chain of the lower limbs, causing structural overload and dysfunction. ${ }^{1,2}$ Pelvic stability is achieved when passive (bones, joints, and ligaments), active (muscles and fascia), and control (neural) systems work together. ${ }^{3}$

There seems to be an adequate balance between pelvic girdle stability and mobility in healthy people, ${ }^{4}$ with lumbar-pelvic stabilization failure seeming to be one of the main mechanisms associated with dysfunctional processes. ${ }^{5}$ The inability to control pelvic anteversion can result in excessive lumbar lordosis and posterior trunk displacement, ${ }^{2}$ which can increase lower back pain. ${ }^{4}$ On the other hand, decreased pelvic anteversion was also observed in patients with low back and sacroiliac pain. ${ }^{6}$ This phenomenon has been related to changes in the muscle activation pattern and deconditioning of the stabilizer muscles. ${ }^{6}$

A study by Hungerford et al., ${ }^{3}$ compared the stability of the pelvis in hip flexion between people with posterior pelvic pain and a control group, and concluded that excessive pelvic anteversion is indicative of failure of the stabilization mechanism and load transfer across the pelvis. These people showed decreased ability to resist vertical loads during weight-bearing exercise. Complementarily, iliac retroversion seems to be a normal component for optimal pelvic stabilization. ${ }^{3}$

The function of different portions of the gluteus maximus, gluteus medius, and tensor fascia lata muscles as the main triplanar muscles of the hip joint is already well described in the literature $;^{7,8}$ however, its role in pelvic anteversion and retroversion movements has not been described. The upper portion of the gluteus maximus, for example, can stabilize the pelvis in the frontal plane, while its lower fibers cannot. ${ }^{2}$ Interestingly, gluteus maximus weakness has been associated with prolonged sitting periods. ${ }^{9}$ The lower capacity of the gluteus maximus for neuromuscular activation seems to be associated with lower back pain, potentially causing instability and sacroiliac dysfunction. ${ }^{10}$

Although some studies analyzed muscle activation in trunk and pelvis control, no studies describing muscle activation on the pelvis in active pelvic anteversion and retroversion in an orthostatic position were found in the literature. This information may be relevant for adequate clinical assessment and treatment practices for dysfunctions related to lack of pelvic control. Thus, the objective of this study was to compare the activation of the tensor fascia lata, gluteus medius, gluteus maximus (upper and lower fibers), and multifidus muscles in pelvic anteversion and retroversion movements.

\section{Methods}

\section{Type of study and ethical aspects}

This was a cross-sectional and exploratory study, part of an integrative project that investigated the kinematics of unilateral squat, of a sample of asymptomatic and 
physically active people. This project was approved by the Research Ethics Committee of the State University of Santa Catarina (CAAE 61338316.3.0000.0118, opinion No. 1.933.707/2017).

\section{Study participants}

The study included 17 asymptomatic and active participants (regular practice of physical exercise) of both sexes. The participants were non-probabilistically recruited through face-to-face or telephone contact in places dedicated to the practice of physical exercises (several modalities).

The inclusion criteria were as follows: (a) age of 18 to 35 years; (b) practice of regular physical exercise (with a minimum duration of 20 minutes per session at least three times a week); ${ }^{11}$ and (c) no complaint of musculoskeletal impairment, orthopedic injuries, and/or history of surgery (lower limbs, spine and upper limbs), cardiovascular, pulmonary, neurological and/or systemic diseases that could limit the performance of the tests in the first contact/interview.

All participants were informed about the research procedures and agreed to participate in the study by signing the informed consent form.

\section{Instruments}

Each participant's body mass and height were measured using a mechanical scale with capacity of up to $150 \mathrm{~kg}$ (Filizola ${ }^{\circledR}, 0.1 \mathrm{~kg}$ accuracy) and a portable stadiometer (Wiso, $0.01 \mathrm{~m}$ accuracy), respectively. The pelvic movement in the sagittal plane (anteversion and retroversion) was kinematically analyzed using the Vicon-Nexus ${ }^{\circledR}$ system (Vicon ${ }^{\circledR}$ Motion Systems, USA) with 10 integrated infrared cameras having a frequency of $100 \mathrm{~Hz}$. All cameras were connected to a computer with the system's software (Vicon-Nexus ${ }^{\circledR}$, version 2.1.1) used to acquire and export the three-dimensional (3D) coordinates of a set of reflective markers positioned on the research subject (according to the biomechanical model subsequently described).

Lower limb and trunk muscle activity was measured using the TeleMyo DTS Desk Receiver electromyograph and the Myomuscle v. 3.8 software (Noraxon Inc., USA). Passive silver chloride electrodes $(4 \times 2.2 \mathrm{~cm}$ adhesive area and $1 \mathrm{~cm}$ conductive area) with a bipolar configuration were used for data acquisition at a rate of
1,500 Hz. Kinematic and electromyographic data were synchronized using a device (Noraxon Inc., USA) that emitted a light signal registered in the Vicon-Nexus ${ }^{\circledR}$ system and a pulse (square wave) recorded in the electromyographic system at the same time.

\section{Collection procedures}

For the kinematic analysis, 32 retro-reflective spherical markers (14 $\mathrm{mm}$ in diameter) were fixed to the participant using double-sided tape $\left(3 \mathrm{M}^{\circledR}\right.$, Brazil). The markers were positioned in the jugular notch, xiphoid process, seventh cervical spinous process, tenth thoracic spinous process; and bilaterally in the acromion, anterior superior iliac spine, posterior superior iliac spine, greater femoral trochanter, lateral thigh, medial femoral epicondyle, fibular head, tibial tuberosity, lateral malleolus, first metatarsal head, fifth metatarsal head, and calcaneus.

This set of markers was used to implement a 3D biomechanical link-segment model that estimates the position of the joint centers and calculates the 3D kinematics of the trunk, pelvis, thigh, leg, and foot segments. The markers were placed by a single previously trained evaluator (CGS) in all collections. Only data from the pelvis segment (formed by the right anterior superior iliac spine, left anterior superior, right posterior superior, and left posterior superior iliac spine markers) were used in this study.

For the electromyographic analysis, the adhesive electrodes were placed in pairs (with $20 \mathrm{~mm}$ between them) and the electromyograph sensors were glued to the skin previously cleaned with a cotton soaked in $70 \%$ alcohol. The electrode arrangement is illustrated in Figure 1. In the upper gluteus maximus (UGMax), the electrodes were placed two fingers above the midpoint between the posterior superior iliac spine and the greater trochanter of the femur; in the lower gluteus maximus (LGMax), they were placed two fingers below this same line. ${ }^{12}$ In the gluteus medius (GMed), the electrodes were placed on the midpoint between the iliac crest and the greater trochanter of the femur; in the tensor fascia lata (TFL), they were placed on the proximal $1 / 6$ between the anterior superior iliac spine and the lateral condyle of the femur; and in the multifidus (MF), the electrodes were placed at the level of L5, on a line drawn from the caudal end of the anterior superior iliac spine to the interspace between L1-L2 . ${ }^{13}$ 

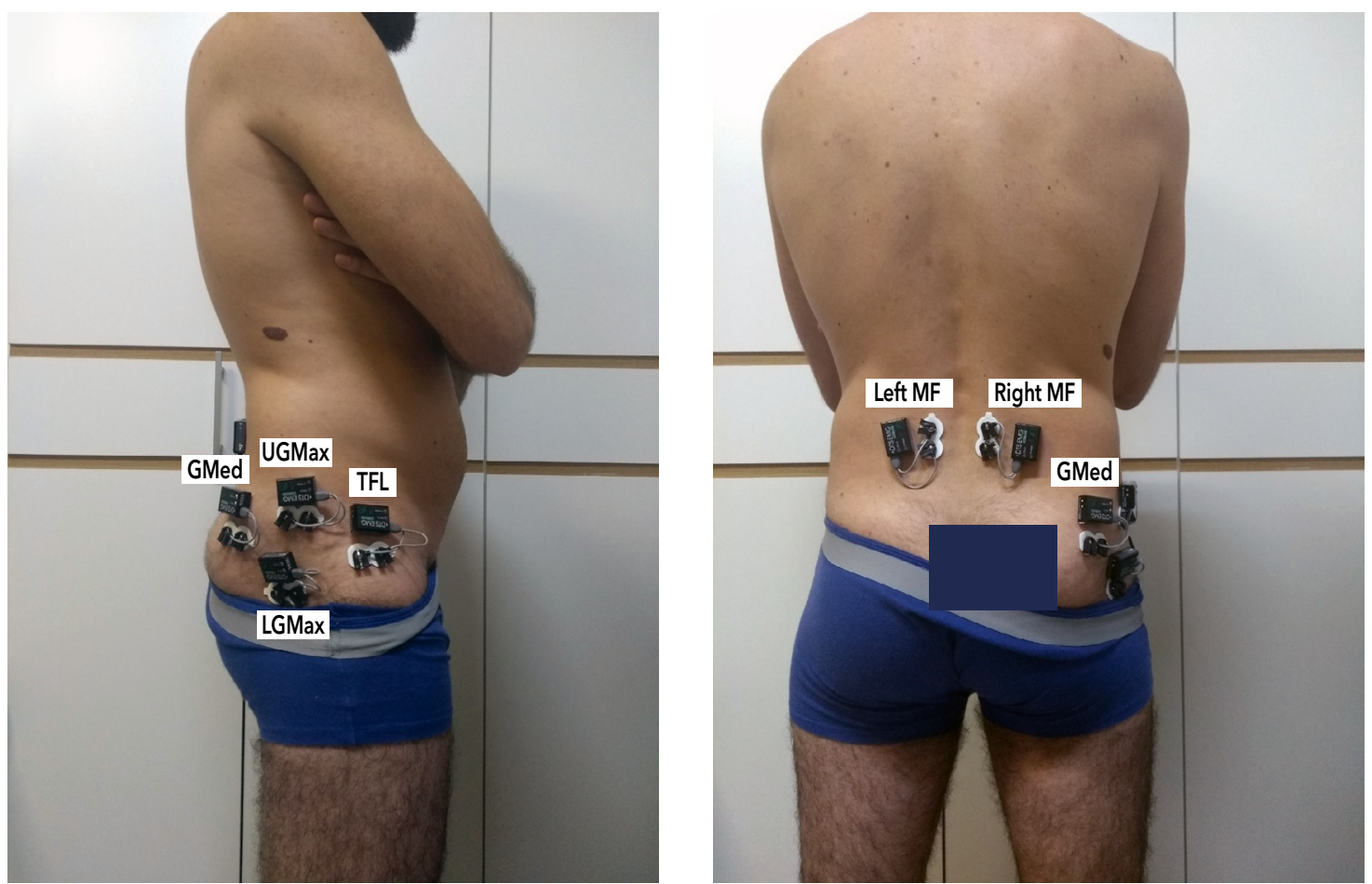

Figure 1 - Electrode arrangements on the analyzed muscles. UGMax = upper gluteus maximus; LGMax = lower gluteus maximus; $\mathrm{TFL}=$ tensor fascia lata; $\mathrm{GMed}=$ gluteus medius; $\mathrm{MF}=$ multifidus.

Once the participant was prepared, maximal voluntary isometric contraction (MVIC) was measured according to the SENIAM guidelines, ${ }^{14}$ for further normalization of the electromyographic data. After familiarization, two maximum contractions of 5 seconds were performed, with an interval of 2 minutes between them. All participants received vigorous verbal encouragement during the tests.

GMed and TFL MVIC was performed with the participant in the lateral decubitus position, performing an abduction against the resistance of a tape placed over the lateral condyle of the femur with the hip in a neutral position. A second tape was used to stabilize the pelvis in the iliac crest region, just above the GMed electrodes. UGMax and LGMax MVIC was evaluated with the participant in the prone position on a stretcher, with $0^{\circ}$ hip flexion and $90^{\circ}$ knee flexion. A tape was firmly placed around both the iliac crests and the stretcher to stabilize the pelvis during the test. A second tape was placed around the posterior distal thigh and the stretcher to provide hip extension resistance. MF MVIC was assessed with the participant in a prone position with the anterior superior iliac spines aligned with the edge of the stretcher. To stabilize the participant, two tapes were used, one on the gluteal fold and the other on the gastrocnemius muscles. During the test, the participant performed trunk extension in a neutral position, against the resistance offered by the researchers.

Then, a training process for the anteversion and retroversion movement was started. The participants were in standing position with slight knee flexion and were instructed to perform pelvic anteversion and retroversion in the widest possible range. After becoming familiarized with the movement, each participant performed five sequential repetitions of maximal pelvic anteversion and retroversion.

\section{Data analysis}

The data obtained from the kinematic analysis were filtered using the Woltring filter and exported in *.c3d

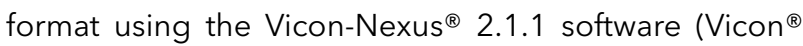
Motion Systems, USA). Then, a 3D biomechanical model was implemented in the Visual3D v6.00.16 software (C-Motion Inc., USA). The global coordinate system was used to reconstruct the pelvis kinematics. 
Electromyographic signals were filtered with a bandpass filter between $10-500 \mathrm{~Hz}$. Then, smoothing was performed using an RMS envelope using a $100 \mathrm{~ms}$ wide window. The electromyographic activity of the analyzed muscles was normalized by the corresponding MVIC. ${ }^{15}$

The synchronization between kinematics and electromyography systems made it possible to demarcate the pelvic anteversion and retroversion movements during electromyographic activity (Figure 2). The first and last movements were deleted. The mean muscle activity of the three central anteversion and retroversion repetitions was extracted. The dependent variable of the present study is the mean activation for each of the analyzed muscles, expressed as a percentage of MVIC (\%MVIC).

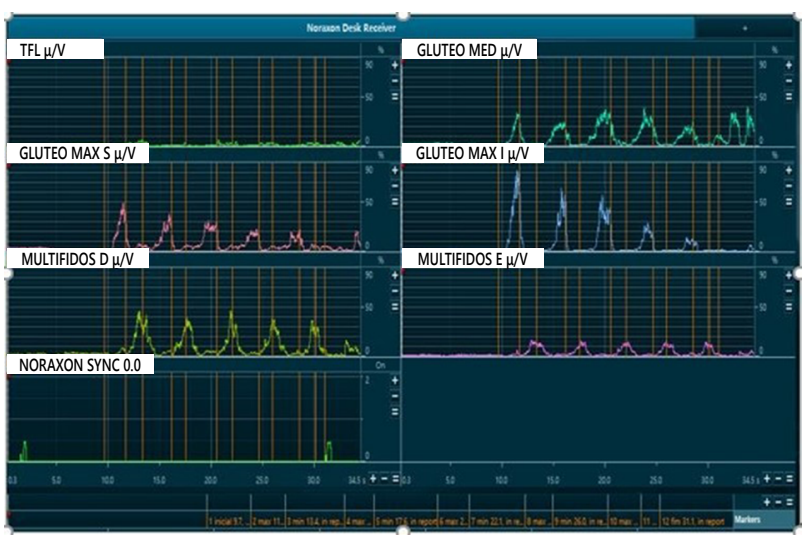

Figure 2 - Electromyographic signal of a participant after signal treatment and anteversion and retroversion movement demarcation.

\section{Results e discussion}

This study aimed at comparing the electromyographic activity of the pelvis muscles in anteversion and retroversion movements. The sample included eight male and nine female participants with a mean age of $25.3 \pm 4.6$ years, body mass $66.9 \pm 7.7 \mathrm{~kg}$, height $1.67 \pm$ $0.05 \mathrm{~m}$, and body mass index $23.9 \pm 2.5 \mathrm{~kg} \cdot \mathrm{m}^{-2}$.

Similar muscle activation levels were observed for TFL, GMed, and UGMax between movements. Greater muscle activity was observed for LGMax in retroversion and for both MFs in pelvic anteversion (Table 1).

The results showed greater LGMax activity in retroversion and greater multifidus activity in anteversion. GMed and TFL showed a low and similar activation level in anteversion and retroversion. The UGMax showed similar activation between the two movements, but with greater magnitudes regarding the MVIC.

The GMax originates from a variety of sites (ilium surface behind the posterior gluteal line, gluteus medius fascia, thoracolumbar fascia, spinal aponeurosis, dorsal sacroiliac ligament, sacrotuberous ligaments, sacral portions, and upper coccyx) to form a broad, square muscle. ${ }^{16}$ Its main anatomical action is to extend the hips, but during locomotion it can provide weight support, propulsion, and trunk forward inclination control. ${ }^{16}$

The results of the present study indicate greater LGMax activity in retroversion, indicating its role in reacting to external or internal movements that cause anteversion. The UGMax, on the other hand, presented a relevant magnitude of activation for both anteversion and retroversion, thus suggesting the importance of this muscle portion for both movements, possibly with a role in stabilizing the pelvis.

Previous studies ${ }^{17,18}$ analyzed the gluteus maximus portions separately and showed greater UGMax activation as a hip abductor and external rotator, while LGMax played a greater extensor role. This finding suggests that GMax upper and lower fibers should be considered separately by the clinical area and may explain the findings of the present study.

With the torso fixed, the hip extensors work in conjunction with the abdominal muscles to retrovert the pelvis. ${ }^{4}$ Thus, excessive anteversion of the pelvis can occur due to GMax weakness or activation delay during hip extension. ${ }^{9,19}$ Although the trunk musculature plays an important role in stabilizing the spine, these muscles are not expected to prevent compensatory trunk movements due to poor control of the pelvis. Therefore, pelvis stability is important to protect the joints of both the knee and the lower back during gait. ${ }^{2}$

The study by Takaki et al. ${ }^{20}$ also analyzed pelvic anteversion and retroversion movements, exploring the electromyographic activity of trunk and lower limb muscles. The authors reported a mean GMax activation (also normalized by MVIC) of $0.5 \%$ and $8 \%$ in anteversion and retroversion, respectively. The mean right and left MF activation corresponded to $24 \%$ and $24 \%$ in anteversion and $3 \%$ and $6 \%$ in retroversion, respectively. According to the authors, the right and left MF presented greater activation in anteversion than the other muscles analyzed. The present study confirms the important participation of MF in anteversion. MF are important lumbar stabilizers and seem to be the first extensor muscles to present 
atrophy in people with low back pain, ${ }^{21}$ being a good health indicator for the region.

In retroversion, Takaki et al. ${ }^{20}$ demonstrated that the most active muscles were the transversus abdominis and gluteus maximus. The results of the present study suggest that only the lower fibers of the GMax are specialized in containing anteversion, while the upper fibers are active in both retroversion and anteversion.

GMed could also have a stabilizing function in the sagittal plane since its middle and posterior portions are considered secondary extensors; ${ }^{4}$ however, there was no difference in GMed activity between movements. According to Powers, ${ }^{2}$ although GMed helps in the extension and external rotation of the hip, its contribution to these movements is not significant.

TFL also showed no activity differences between the movements performed. Imbalanced muscle activation, with TFL dominating the GMax and semitendinosus muscles in hip extension, can lead to abnormal movement patterns, with anterior pelvic tilt and excessive lumbar extension. ${ }^{9}$ Although kinematic changes were not controlled in the present study, the participation of healthy and physically active people in the analysis may have contributed to more harmonic pelvic stability findings. These results suggest that TFL practically has no function in anteversion and retroversion movements.

Table 1 - Mean (standard deviation) electromyographic activity of the pelvis muscles as a percentage of MVIC (\%MVIC), t- and p-values obtained in the comparison test and $95 \% \mathrm{Cl}$ of the mean difference between movements

\begin{tabular}{lccccc}
\hline $\begin{array}{l}\text { Mean activation } \\
\text { (\%CVIM) }\end{array}$ & Anteversion & Retroversion & t & P & $\begin{array}{c}\mathbf{9 5 \%} \mathbf{C l} \\
\text { of the difference }\end{array}$ \\
\hline TFL & $2.7(1.8)$ & $2.9(2.5)$ & -0.9 & 0.393 & $-0.8-0.3$ \\
GMed & $6.5(2.9)$ & $9.4(6.8)$ & -2.0 & 0.067 & $-5.9-0.2$ \\
UGMax & $14.9(15.1)$ & $15.5(13.3)$ & -0.5 & 0.593 & $-3.1-1.9$ \\
LGMax & $5.0(3.2)$ & $7.9(5.5)$ & -2.5 & 0.025 & $-5.3--0.4$ \\
Right MF & $16.4(4.4)$ & $11.7(4.5)$ & 4.6 & $<0.001$ & $2.6-6.9$ \\
Left MF & $15.8(6.1)$ & $11.1(4.7)$ & 2.8 & 0.014 & $1.1-8.4$ \\
\hline
\end{tabular}

Note: TFL = tensor fascia lata; GMed = gluteus medius; UGMax = upper gluteus maximus; LGMax = lower gluteus maximus; MF = multifidus; $\mathrm{MVIC}=$ maximal voluntary isometric contraction; $\mathrm{Cl}=$ confidence interval.

Exploring temporal aspects related to the activation of muscles that contribute to pelvic movement could be interesting. Initially, the presence of onset and offset muscle recruitment instants was analyzed in an exploratory in pelvic anteversion and retroversion, but the investigated muscles showed no clearly defined pattern. There seems to be a constant recruitment throughout the movement, with three muscles (right and left multifidus and inferior gluteus maximus) showing different activation magnitudes between movements. However, even these three muscles presented greater activation than that observed at baseline throughout the movement. Thus, it was decided not to analyze aspects related to the pattern of muscle recruitment. Additionally, the data reported in this research should not be extrapolated to patient populations, considering that only healthy participants were analyzed. Finally, the participants were not evaluated for the presence of postural changes in the pelvis and hip region. Further investigations are necessary to assess whether they have any influence on the activation of the analyzed muscles.

\section{Conclusion}

LGMax activity was more significant in retroversion, while the MF was more active in pelvic anteversion. UGMax showed a relevant level of activation in both movements, while TFL and GMed presented low similar values between movements. These results encourage the development of further studies to determine whether a posture with excess pelvic anteversion may be associated with excessively increased MF activation 
or, for patients with excessive pelvic retroversion, whether LGMax is being overly recruited. In addition, the substantial UGMax recruitment indicates the role of a pelvic stabilizer, and could thus be an important muscle to be evaluated in cases where adequate lumbar-pelvic control is difficult in functional movements.

\section{Acknowledgments}

This study had the support of the State University of Santa Catarina (Universidade do Estado de Santa Catarina - UDESC), for which the authors are very grateful. In addition, the authors would like to thank the Coordination for the Improvement of Higher Education Personnel (Coordenação de Aperfeiçoamento de Pessoal de Nível Superior - CAPES) and the Foundation for Research and Innovation Support of the State of Santa Catarina (Fundação de Amparo à Pesquisa e Inovação do Estado de Santa Catarina - FAPESC) (grant terms 2019TR602, 2017TR764 and 2017TR788).

\section{Authors' contribution}

All authors contributed significantly to the manuscript and participated in the design, methodology, data analysis and interpretation, writing, critical review of the article, and approval of the final version to be published.

\section{References}

1. Graci V, Van Dillen L, Salsich GB. Gender differences in trunk, pelvis and lower limb kinematics during single leg squat. Gait Posture. 2012;36(3):461-6. DOI

2. Powers $\mathrm{CM}$. The influence of abnormal hip mechanics on knee injury: a biomechanical perspective. J Orthop Sports Phys Ther. 2010;40(2):42-51. DO|

3. Hungerford B, Gilleard W, Lee D. Altered patterns of pelvic bone motion determined in subjects with posterior pelvic pain using skin markers. Clin Biomech (Bristol, Avon). 2004;19(5):45664. DOI

4. Neumann DA. Kinesiology of the hip: a focus on muscular actions. J Orthop Sports Phys Ther. 2010;40(2):82-94. DOI
5. Hodges PW, Ricardson CA. Inefficient muscular stabilization of the lumbar spine associated with low back pain. A motor control evaluation of transversus abdominis. Spine (Phila Pa 1976). 1996;21(22):2640-50. DOI

6. Kuszewiski MT, Gnat R, Gogola A. The impact of core muscles training on the range of anterior pelvic tilt in subjects with increased stiffness of the hamstring. Hum Mov Sci. 2018;57:32 9. DOI

7. Delp SL, Hess WE, Hungerford DS, Jones LC. Variation of rotation moment arms with hip flexion. J Biomech. 1999;32(5): 493-501. DOI

8. Dostal WF, Soderberg GL, Andrews JG. Actions of hip muscles. Phys Ther. 1986;66(3):351-61. DOI

9. Choi SA, Cynn HS, Yi CH, Know OY, Yoon TL, Choi WJ, et al. Isometric hip abduction using a Thera-Band alters gluteus maximus muscle activity and the anterior pelvic tilt angle during bridging exercise. J Electromyogr Kinesiol. 2015;25(2): 310-5. DOI

10. van Wingerden JP, Vleeming A, Buyruk HM, Raissadat K. Stabilization of the sacroiliac joint in vivo: verification of muscular contribution to force closure of the pelvis. Eur Spine J. 2004;13(3):199-205. DOI

11. Blackburn JT, Padua DA. Sagittal-plane trunk position, landing forces, and quadriceps electromyographic activity. J Athl Train. 2009;44(2):174-9. DOI

12. Fujisawa $H$, Suzuki $H$, Yamaguchi $E$, Yoshiki $H$, Wada $Y$, Watanabe A. Hip muscle activity during isometric contraction of hip abduction. J Phys Ther Sci. 2014;26(2):187-90. DOI

13. Hermens HJ, Freriks B, Disselhorst-Klug C, Rau G. Development of recommendations for SEMG sensors and sensor placement procedures. J Electromyogr Kinesiol. 2000; 10(5):361-74. DOI

14. SENIAM. Surface ElectroMyoGraphy for the Non-Invasive Assessment of Muscles [cited 2020 Nov 30]. Available from: http://www.seniam.org

15. Yang JF, Winter DA. Electromyographic amplitude normalization methods: improving sensitivity as diagnostic tools in gait analysis. Arch Phys Med Rehabil. 1984;65(9):51721. Full text link 
16. Bartlett JL, Sumner B, Ellis RG, Kram R. Activity and functions of the human gluteal muscles in walking, running, sprinting, and climbing. Am J Phys Anthropol. 2014;153(1):124-31. DOI

17. Selkowitz DV, Beneck GJ, Powers CP. Comparison of electromyographic activity of the superior and inferior portions of the gluteus maximus muscle during common therapeutic exercises. J Orthop Sports Phys Ther. 2016;46(9):794-9. DOI

18. Chan MKY, Chow KW, Lai AYS, Mak NCK, Sze JCH, Tsang $\mathrm{SMH}$. The effects of therapeutic hip exercise with abdominal core activation on recruitment of the hip muscles. BMC Musculoskelet Disord. 2017;18:313. DOI
19. Yoon JY, Lee MR, An DH. Effect of initial position on the muscle activity of the hip extensors and amount of pelvic tilt during prone hip extension. J Phys Ther Sci. 2015;27(4):1195-7. DOI

20. Takaki S, Kaneoka K, Okubo Y, Otsuka S, Tatsumura M, Shiina I, et al. Analysis of muscle activity during active pelvic tilting in sagittal plane. Phys Ther Res. 2016;19(1):50-7. DOI

21. Beneck GJ, Story JW, Donald S. Postural cueing to increase lumbar lordosis increases lumbar multifidus activation during trunk stabilization exercises: electromyographic assessment using intramuscular electrodes. J Orthop Sports Phys Ther. 2016;46(4):293-9. DOI 